\title{
Effects of selected surfactants on purified glucosyltransferases from mutans streptococci and cellular adherence to smooth surfaces
}

\author{
S. KAWABATA, M. TORII, T. MINAMI, T. FUJIWARA and S. HAMADA $\dagger$
}

Department of Oral Microbiology, Osaka University Faculty of Dentistry, Suita-Osaka, 565 Japan

\begin{abstract}
Summary. The inhibitory effect of non-ionic, anionic, cationic and ampholytic surfactants on cellular growth of Streptococcus mutans MT8148 and S. sobrinus 6715, on glucan synthesis by the purified glucosyltransferase (GTase) from these organisms, and on bacterial adherence to glass surfaces was examined in ritro. Cationic surfactants exhibited marked bactericidal activities. Anionic and ampholytic compounds were less strongly bactericidal and non-ionic surfactants produced only slight inhibition of cell growth under the conditions tested. Some non-ionic compounds had no effect on this. Glucan synthesis by GTase from mutans streptococci was inhibited by anionic and cationic surfactants. Among various GTase proteins. insoluble glucan synthesising GTases, i.e., S. mutans CA-GTase and S. sobrinus GTase-I were those most effectively inhibited by these agents. However, it was noted that whereas lower concentrations of cationic surfactants enhanced these GTase activities, higher concentrations of the surfactants were inhibitory. Non-ionic detergents stimulated soluble glucan synthesis from S. mutans CF-GTase and cationic and ampholytic surfactants enhanced or inhibited glucan synthesis depending on the concentrations of the surfactants. Sucrosedependent cellular adherence of resting cells of mutans streptococci to glass surfaces was inhibited by the addition of surfactants that annulled the GTase activities.
\end{abstract}

\section{Introduction}

There is strong evidence that synthesis of adherent. water-insoluble glucans from sucrose by glucosyltransferases (GTases) of mutans streptococci, including Streptococcus mutans and $S$. sobrimus, is an important factor in the induction of dental caries.' When mutants of these organisms lose their ability to synthesise such glucans they exhibit markedly decreased cariogenicity in experimental animals. ${ }^{2.3}$ It is, therefore, logical to consider that to inhibit glucan formation in mutans streptococci is a valid strategy for restricting adherence and persistent colonisation by these caries-inducing organisms. ${ }^{+}$

A number of substances have been reported as possible inhibitors of GTases. Natural compounds, e.g., cocoa extract ${ }^{5}$ and tea extracts ${ }^{\text {t. }}{ }^{7}$ are known to contain GTase-inhibitory constituents, and it has also been shown that some amino sugar derivatives. such as acarbose and nojirimycin, and glycyrrhizin, a saponin of liquorice. inhibit the synthesis of insoluble glucans by GTase from mutans streptococci. ${ }^{8,9}$ Oligosaccharides containing $x$-linked glucosidic linkages such as maltose. isomaltose and panose, ${ }^{10.11}$ dextrans. ${ }^{12}$ structural isomers of sucrose such as

Received 8 May 1992: revised version accepted 29 May 1992 $\div$ Correspondence should be sent to Professor S. Hamada. palatinose and trehalulose, ${ }^{13}$ and maltitol, a disaccharide sugar alcohol that contains $\alpha(1 \rightarrow 4)$ linkage $^{14}$ also suppress GTase activity significantly.

Dental plaque accumulation can be controlled by topical applications of dentifrices or the use of mouth rinses that contain surfactants of detergents, whose surface activity is produced by the hydrophilic (polar) and hydrophobic (hydrocarbon or non-polar) moieties of their molecules. ${ }^{15.16}$ Surfactants have been classified most commonly as anionic, cationic, ampholytic and non-ionic, depending on the nature of their electrical charges. ${ }^{17}$ Some surfactants exhibit antienzyme and antimicrobial activities. ${ }^{18-20}$

No comparison has been attempted, however, to determine the effects of detergents of different formulations on highly purified GTases, cellular growth and adherence of mutans streptococci. This paper describes the effects of representative detergent compounds on these factors.

\section{Materials and methods}

\section{Organisms}

S. mutans MT8148 (serotype $c$ ) and S. sobrinus 6715 (serotype $g$ ) were selected from the culture collection at the Department of Oral Microbiology, Osaka University Faculty of Dentistry, Suita-Osaka. They were 
Table I. Minimum inhibitory concentrations (MICs) of selected surfactants for $S$. mutans MT8148 and S. sobrinus 6715

\begin{tabular}{|c|c|c|}
\hline \multirow{2}{*}{ Surfactant } & \multicolumn{2}{|c|}{$\operatorname{MIC}(\mu \mathrm{g} / \mathrm{ml})^{*}$} \\
\hline & MT8148 & 6715 \\
\hline \multicolumn{3}{|l|}{ Anionic } \\
\hline $\begin{array}{l}\text { Sodium dodecyl sulphate } \\
\text { (SDS) }\end{array}$ & $40 \cdot 0(14 \cdot 1)$ & $50 \cdot 0(14 \cdot 1)$ \\
\hline $\begin{array}{l}\text { Sodium di 2-ethylhexyl } \\
\text { sulphosuccinate }\end{array}$ & $70 \cdot 0(17 \cdot 5)$ & $167 \cdot 7(58 \cdot 9)$ \\
\hline \multicolumn{3}{|l|}{ Cationic } \\
\hline $\begin{array}{l}\text { Cetyltrimethylammonium } \\
\text { bromide (CTAB) }\end{array}$ & $0.030(0.016)$ & $0.030(0.016$ \\
\hline $\begin{array}{l}\text { Cetylpyridinium chloride } \\
\text { (CPC) }\end{array}$ & $0.030(0.011)$ & $0.050(0.035)$ \\
\hline \multicolumn{3}{|l|}{ Ampholytic } \\
\hline $\begin{array}{l}\text { Lauryldimethylamino- } \\
\text { acetic acid betaine }\end{array}$ & $450 \cdot 0(141 \cdot 4)$ & $250 \cdot 0(70 \cdot 7)$ \\
\hline $\begin{array}{l}\text { Alkyl diaminoethyl } \\
\text { glycine }\end{array}$ & $40 \cdot 0(14 \cdot 1)$ & $35 \cdot 0(18 \cdot 7)$ \\
\hline \multicolumn{3}{|l|}{ Non-ionic } \\
\hline $\begin{array}{l}\text { Octylphenol-ethylene } \\
\text { oxide (Nonidet P-40) }\end{array}$ & $450 \cdot 0(212 \cdot 1)$ & $350.0(187.0)$ \\
\hline $\begin{array}{l}\text { POE (20) Sorbitan } \\
\text { monolaurate (Tween } 20 \text { ) }\end{array}$ & NI & NI \\
\hline
\end{tabular}

* Data are expressed as the mean (SD) of triplicate experiments. NI, not inhibitory.

grown in Todd-Hewitt Broth (Difco) supplemented with glucose $0.5 \% \mathrm{w} / \mathrm{v}$ and incubated at $37^{\circ} \mathrm{C}$ for $18 \mathrm{~h}$. Cells were harvested by centrifugation, washed three times with distilled water, and lyophilised.

\section{Chemicals}

Sodium dodecyl sulphate, cetylpyridinium chloride, and polyoxyethylene (20) sorbitan monolaurate [POE (20)] were purchased from Wako Pure Chemicals, Osaka, Japan. Cetyltrimethylammonium bromide was purchased from Nakarai Chemicals, Kyoto, Japan, and octylphenol-ethylene oxide was from Sigma. $\left[{ }^{14} \mathrm{C}\right.$ glucose]sucrose was obtained from New England Nuclear Corp., MA, USA. Sodium di 2-ethylhexyl sulphosuccinate, lauryldimethylaminoacetic acid betaine and alkyl diaminoethyl glycine were kindly supplied by Y. Yamamoto, Sunstar Inc., Osaka, Japan.

\section{Preparation of glucosyltransferases (GTases)}

S. mutans MT8148 and S. sobrinus 6715 were grown in $8 \mathrm{~L}$ of diffusate medium of TTY broth for $18 \mathrm{~h}$ and $37^{\circ} \mathrm{C} .{ }^{21}$ The supernate from each culture was concentrated by passing it through an ultrafiltration module (Model ACL-1010, Asahi Chemical Industry, Tokyo, Japan), and salted out by $50 \%$ saturated ammonium sulphate. The precipitate was dialysed against $10 \mathrm{~mm}$ potassium phosphate buffer $(\mathrm{pH} \mathrm{6.0)}$ ), and used as a crude cell-free GTase preparation.

The crude cell-free GTase (CF-GTase) of $S$. mutans MT8148 was further purified by the chromatofocussing method with a Polybuffer exchanger PBE94
(Pharmacia LKB Biotechnology, Uppsala, Sweden).$^{22}$ This enzyme produced mainly water-soluble glucan (SG) from sucrose. Cell-associated GTase (CAGTase) synthesising water-insoluble glucan (IG) was extracted from whole cells of $S$. mutans MT8148 by treatment with $8 \mathrm{M}$ urea at $25^{\circ} \mathrm{C}$ for $1 \mathrm{~h}$, and the extract was purified by DEAE-Sephacel (Pharmacia) column chromatography as described previously. ${ }^{23}$

GTase-I synthesising IG, and two GTases synthesising SG (GTase-Sa and GTase-Sb) were isolated from the crude cell-free GTase of S. sobrinus 6715 by the chromatofocussing methods as described previously. ${ }^{24}$ It was noted that GTase-Sa was primerindependent and GTase-Sb primer-dependent. ${ }^{25}$

\section{Minimum inhibitory concentrations (MICs) of surfactants}

Two-fold dilutions of the surfactants were made to provide a range of concentrations from 1 to $0.00001 \%$; $100 \mu \mathrm{l}$ of each solution was placed into wells of the flatbottomed 96-well plate (Corning Glass Works, Corning, NY, USA). Subsequently, $100 \mu$ l containing $1 \times 10^{6} \mathrm{cfu}$ of an overnight culture of organisms suspended in $2 \times$ concentrated Brain Heart Infusion Broth (Difco) was inoculated into each well. After the plate was incubated at $37^{\circ} \mathrm{C}$ for $48 \mathrm{~h}$, the MIC was determined as the lowest concentration of surfactant that caused complete inhibition of growth of the indicator organisms.

\section{Glucan synthesis in the presence of surfactants}

Synthesis of IG was measured turbidimetrically by increased absorbance at $550 \mathrm{~nm}$ after IG-synthesising GTase $(10-20 \mathrm{mU})$ was incubated in $2 \mathrm{ml}$ of $50 \mathrm{~mm}$ sodium phosphate buffer $(\mathrm{pH} 6.0$; hereafter designated $\mathrm{NaPB}$ ) containing sucrose $1 \%$, sodium azide $0.05 \%$ and surfactants in the presence or absence of primer Dextran T10 $(20 \mu \mathrm{M}$, Pharmacia $)$ at $37^{\circ} \mathrm{C}$ for $18 \mathrm{~h}$.

For the measurement of SG synthesis, SG-synthesising GTase was allowed to react with $10 \mathrm{~mm}\left[{ }^{14} \mathrm{C}\right.$ glucose]sucrose $(1.85 \mathrm{GBq} / \mathrm{mol})$ and various concentrations of surfactants, with or without Dextran T10 in $0 \cdot 1 \mathrm{~m} \mathrm{NaPB}, \mathrm{pH} 6 \cdot 0$. After incubating at $37^{\circ} \mathrm{C}$ for $1 \mathrm{~h}$, this was spotted onto a filter paper $(7.5 \times 15.0 \mathrm{~mm}$, no. 514A; Toyo Roshi, Tokyo, Japan), washed three times with methanol $100 \%$ and dried. Radioactivity of $\left[{ }^{14} \mathrm{C}\right]$ glucan synthesised was quantitated by placing the filter paper in a scintillation counter (Model 1214, Pharmacia) as described by Koga et $a l^{2}$ One unit of GTase activity was defined as the amount of enzyme that transformed $1 \mu \mathrm{mol}$ of sucrose to glucan $/ \mathrm{min}$ under the conditions described above.

\section{Adherence of resting cells to a glass surface}

To assess the inhibition of sucrose-dependent adherence of mutans streptococci to the surface of a glass 

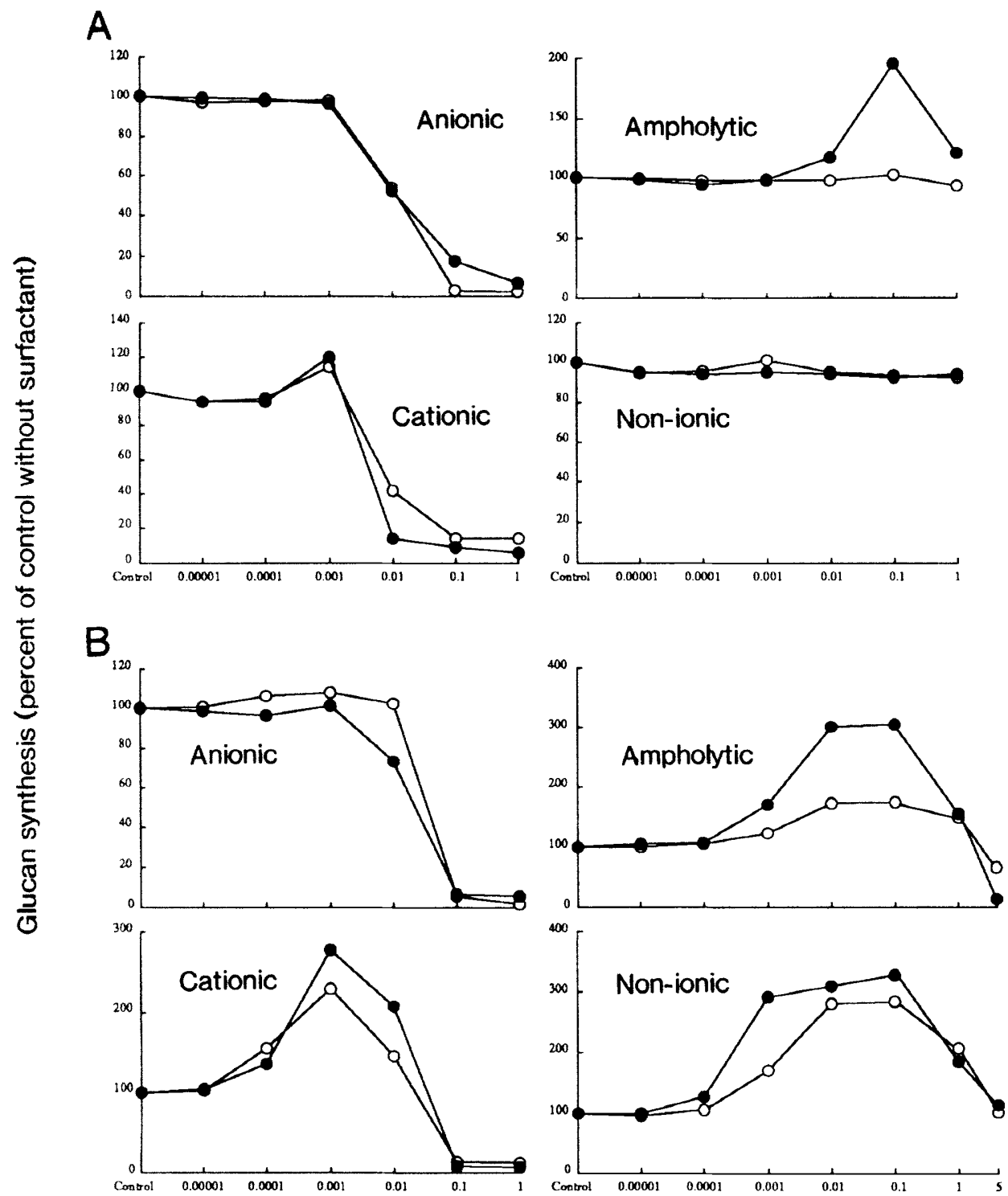

\section{Concentration (\%)}

Fig. 1. Effects of surfactants on water-insoluble glucan synthesis of CA-GTase (A) and on water-soluble glucan synthesis of CF-GTase (B) from $S$. mutans MT8148. CA-GTase was assayed without $10 \mu \mathrm{M}$ Dextran T10;CF-GT ase was assayed with $10 \mathrm{~mm}\left[{ }^{14} \mathrm{C}\right.$-glucose]sucrose in the presence of $10 \mu \mathrm{m}$ Dextran T10. Anionic surfactants-sodium dodecyl sulphate (-O-), sodium di-2-ethylhexyl sulphosuccinate (- -); cationic-cetyltrimethylammonium bromide $\left(-\mathrm{O}^{-}\right)$, cetylpyridinium chloride $(-\mathbf{-})$; ampholytic-lauryldimethyaminoacetic acid betaine $\left(-\mathrm{O}^{-}\right.$), alkyl di-aminoethyl glycine (--) : non-ionic-octylphenol-ethylene oxide $\left(-\mathrm{O}^{-}\right)$, POE (20) sorbitan monolaurate $\left(-\mathbf{-}^{-}\right)$.

tube, resting cell suspensions $(1.5 \mathrm{mg} / 3 \mathrm{ml}$ of $50 \mathrm{~mm}$ NaPB containing sodium azide $0.05 \%$ tube) were incubated in sucrose $1 \%$ and various concentrations of surfactants at $37^{\circ} \mathrm{C}$ for $18 \mathrm{~h}$ at an angle of $30^{\circ}$. The quantity of cells that adhered to the glass surface was determined turbidimetrically and expressed as percentage adherence. ${ }^{12}$

\section{Results}

Four different surfactants were ranked with regard to their inhibitory effect on the growth of mutans streptococei as follows: cationic $\gg$ anionic $\geqslant$ ampholytic > non-ionic surfactants (table I). There was no significant difference in MICs of these surfactants between the two strains of $S$. mutans and $S$. sobrinus. Non-ionic detergents such as POE (20) sorbitan monolaurate (Tween 20) (table I), POE (20) sorbitan monooleate (Tween 80), POE (20) nonylphenyl ether, and POE (40) monostearate did not inhibit mutans streptococci. Octylphenol-ethylene oxide (Nonidet P-40) was slightly inhibitory to the growth of mutans streptococci (table I).

In the assessment of the inhibitory effects of various surfactants on glucan synthesis from sucrose by GTases of mutans streptococci, it was found that anionic surfactants were the most effective in inhibiting water-insoluble glucan synthesis by CA-GTase from $S$. mutans. Cationic surfactants also exhibited strong inhibitory effects on CA-GTase. However, these agents activated enzyme activity at a lower concentration, i.e., $0.001 \%$. Although ampholytic and non-ionic surfactants did not influence GTase activity significantly, alkyl diaminoethyl glycine produced a 
Surfactant concentration (\%)
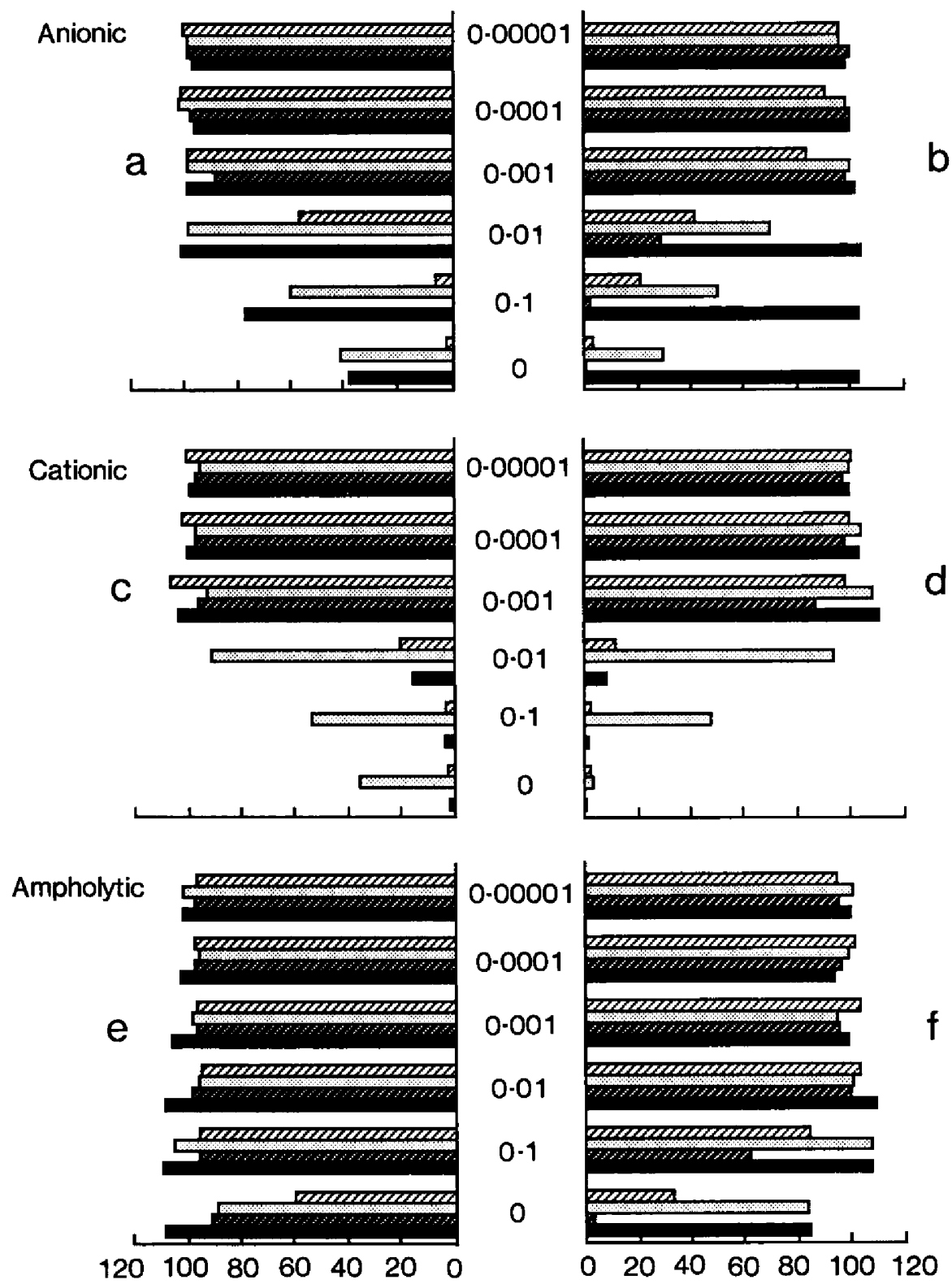

\section{Glucan synthesis (percent of control without surfactant)}

Fig. 2. Effects of surfactants on glucan synthesis of extracellular GTases from S. sobrinus 6715: a, sodium dodecyl sulphate; b, sodium di-2-ethylhexyl sulphosuccinate; c, cetyltrimethylammonium bromide; d, cetylpyridinium chloride; e, lauryldimethylaminoacetic acid betaine; f, alkyl diaminoethyl glycine. Crude GTase $(\mathbb{Z})$ and GTase-Sa () were assayed without $10 \mu \mathrm{M}$ Dextran T10; GTase-I ( $\mathbb{Z}$ ) and GTase-Sb (D) were assayed with $10 \mu \mathrm{m}$ Dextran T10. Data (means of triplicate experiments) are expressed as the ratio of the quantities of glucan synthesised in the presence of surfactant and those without.

two-fold rise in insoluble glucan synthesis at a final concentration of $0 \cdot 1 \%$ (fig. 1A). Water-soluble glucan synthesis due to CF-GTase of $S$. mutans was markedly inhibited by anionic and cationic surfactants at concentrations of $0 \cdot 1-1 \%$. Cationic, ampholytic and non-ionic surfactants enhanced glucan synthesis at lower concentrations, but this was suppressed at higher concentrations (fig. 1B).

Fig. 2 shows the effects of various surfactants on glucan synthesis by crude GTase, GTase-Sa, GTase$\mathrm{Sb}$, and GTase-I of S. sobrinus 6715. In general, cationic and anionic surfactants markedly inhibited insoluble glucan synthesis; GTases synthesising water- soluble glucans were less sensitive to these surfactants. Non-ionic surfactants did not inhibit GTase activity of $S$. sobrinus 6715 . Inhibition of insoluble glucan synthesis by crude GTase upon addition of anionic or cationic detergent was due to specific inhibition of GTase-I present in the crude enzyme preparation.

Inhibition of adherence by the surfactants was tested with resting cells of mutans streptococci cultured in glucose-containing Todd-Hewitt broth. With the exception of two non-ionic compounds, surfactants inhibited significantly sucrose-dependent adherence of $S$. mutans and $S$. sobrinus cells to glass surfaces; adherence of $S$. mutans was enhanced in the presence of 
Table II. Effects of surfactants on sucrose-dependent adherence of resting cells of S. mutans MT8148

\begin{tabular}{|c|c|c|c|c|c|c|c|c|}
\hline \multirow{3}{*}{$\begin{array}{c}\text { Concentration } \\
\text { of surfactant } \\
(\%)\end{array}$} & \multicolumn{8}{|c|}{ Mean percentage (SD) adherence* after treatment with surfactants } \\
\hline & \multicolumn{2}{|c|}{ anionic } & \multicolumn{2}{|c|}{ cationic } & \multicolumn{2}{|c|}{ ampholytic } & \multicolumn{2}{|c|}{ non-ionic } \\
\hline & a & $b$ & $\mathrm{c}$ & $\mathrm{d}$ & $\mathrm{e}$ & f & $\mathrm{g}$ & h \\
\hline 0 & $6.3 \cdot 8(1 \cdot 6)$ & $63.8(1.6)$ & $63.6(1.6)$ & $63.6(1.6)$ & $63.6(1.6)$ & $63.6(1 \cdot 6)$ & $63 \cdot 6(1 \cdot 6)$ & $63.6(1.6)$ \\
\hline $0 \cdot 00001$ & $60 \cdot 3(2 \cdot 0)$ & $58 \cdot 3(1 \cdot 8)$ & $56 \cdot 3(3 \cdot 7)$ & $57.5(0.4)$ & $61 \cdot 8(6 \cdot 3)$ & $63.3(2.7)$ & $61.7(1.4)$ & $62 \cdot 5(1 \cdot 6)$ \\
\hline 0.0001 & $52.7(6.0)$ & $57.6(4 \cdot 1)$ & $56.0(2.8)$ & $49 \cdot 2(3.0)$ & $61.8(3 \cdot 1)$ & $60 \cdot 6(5 \cdot 0)$ & $62 \cdot 4(5 \cdot 3)$ & $61 \cdot 1(1 \cdot 5)$ \\
\hline $0 \cdot 1001$ & $44 \cdot()(4 \cdot 1)$ & $56.7(5.0)$ & $45.4(3.8)$ & $29 \cdot 1(2 \cdot 1)$ & $57.9(2.2)$ & $53.7(3.9)$ & $63.5(6.2)$ & $62.3(2 \cdot 5)$ \\
\hline $0 \cdot 01$ & $55 \cdot 3(5 \cdot 4)$ & $54.8(2.8)$ & $25.6(9.2)$ & $25.4(1.7)$ & $61 \cdot 6(4 \cdot 8)$ & $40 \cdot 8(4.9)$ & $67.8(4 \cdot 5)$ & $64 \cdot 4(6 \cdot 2)$ \\
\hline 0.1 & $2 \cdot 0(0.2)$ & $1.5(0.4)$ & $1.2(0 \cdot 3)$ & $2 \cdot 1(0 \cdot 5)$ & $35 \cdot 1(3 \cdot 1)$ & $61.5(2 \cdot 3)$ & $66 \cdot 2(3 \cdot 0)$ & $72 \cdot 0(2 \cdot 8) \dagger$ \\
\hline 1 & $2.6(1.0)$ & $1.5(0.2)$ & $0.4(0.1)$ & $3.7(0.7)$ & $17 \cdot 1(2.3)$ & $1.9(0.5)$ & $65 \cdot 5(6 \cdot 1)$ & $71.8(5.5)$ \\
\hline
\end{tabular}

* The ratio of cells adhering to the glass surface compared with total cells: mean of triplicate experiments: a: Sodium dodecyl sulphate. b: sodium di 2-ethylhexyl sulphosuccinate, $\mathrm{c}$ : cetyltrimethylammonium bromide, $\mathrm{d}$ : cetylpyridinium chloride, $\mathrm{e}$ : lauryldimethylaminoacetic acid hetaine. $f$ : alkyl diaminoethyl glycine. $h$ : octylphenol-ethylene oxide, g: POE(20) sorbitan monolaurate.

+ Statistical analysis was carried out by the Student's $t$ test between control and the other group $(0.00001-1 \%)$; for non-ionic surfactants (‥ h). $1<0.05$

Table III. Effects of surfactants on sucrose-dependent adherence of resting cells of $S$. sobrinus 6715

\begin{tabular}{|c|c|c|c|c|c|c|c|c|}
\hline \multirow{3}{*}{$\begin{array}{c}\text { Comcentration } \\
\text { of surfactant } \\
\left(\begin{array}{l}0 \\
0\end{array}\right)\end{array}$} & \multicolumn{8}{|c|}{ Mean percentage (SD) adherence after treatment with surfactants } \\
\hline & \multicolumn{2}{|c|}{ anionic } & \multicolumn{2}{|c|}{ cationic } & \multicolumn{2}{|c|}{ ampholytic } & \multicolumn{2}{|c|}{ non-ionic } \\
\hline & $a$ & b & c & $\mathrm{d}$ & $\mathrm{e}$ & $\mathrm{f}$ & $\mathrm{g}$ & $\mathrm{h}$ \\
\hline 0 & $81.7(0.9)$ & $81.7(0.9)$ & $81 \cdot 7(0.9)$ & $81.7(0.9)$ & $81 \cdot 7(0 \cdot 9)$ & $81 \cdot 7(0 \cdot 9)$ & $81.7(0.9)$ & $81.7(0.9)$ \\
\hline$(1) 0000) !$ & $8(0.1(0 \cdot 6)$ & $80.5(0.5)$ & $76 \cdot 5(1 \cdot 1)$ & $81 \cdot 2(1 \cdot 5)$ & $79 \cdot 5(3.7)$ & $75 \cdot 8(1 \cdot 0)$ & $77 \cdot 3(2 \cdot 2)$ & $77.6(1.0)$ \\
\hline 0.0001 & $80.5(0 \cdot 7)$ & $82.5(0.6)$ & $77.0(0.6)$ & $79.7(1.0)$ & $78.7(1.9)$ & $71 \cdot 5(5 \cdot 3)$ & $74 \cdot 3(5 \cdot 6)$ & $79.2(1.9)$ \\
\hline 0.001 & $80 \cdot 2(1.0)$ & $80.8(1.4)$ & $78 \cdot 3(0 \cdot 7)$ & $82 \cdot 6(0 \cdot 3)$ & $75 \cdot 7(1 \cdot 1)$ & $75.0(2.0)$ & $75.6(1.3)$ & $83.3(0.8)$ \\
\hline $0 \cdot 01$ & $65.2(0.7)$ & $60 \cdot 0(1 \cdot 2)$ & $79 \cdot 7(1 \cdot 4)$ & $81 \cdot 2(4.4)$ & $75.7(1.5)$ & $78 \cdot 7(2 \cdot 1)$ & $81 \cdot 8(1 \cdot 2)$ & $81 \cdot 2(2 \cdot 8)$ \\
\hline $0 \cdot 1$ & $0.5(0.2)$ & $0.4(0.4)$ & $2 \cdot 0(0 \cdot 6)$ & $6 \cdot 2(0 \cdot 8)$ & $82.8(3.7)$ & $7 \cdot 8(3 \cdot 1)$ & $80 \cdot 3(0 \cdot 3)$ & $78 \cdot 1(0 \cdot 8)$ \\
\hline 1 & $0.3(0.1)$ & $0.5(0.4)$ & $0.7(0.1)$ & $2.5(0.4)$ & $50.4(2 \cdot 6)$ & $1.8(0.7)$ & $77 \cdot 6(1.0)$ & $78.1(1.5)$ \\
\hline
\end{tabular}

See formote to table II.

POE (20) sorbitan monolaurate $0 \cdot 1 \%$ (tables II and III).

\section{Discussion}

It is known that various agents can affect release of GTases during growth of mutans and other oral streptococci. or modify the enzymic activity of GTases isolated from cultures of mutans streptococci. For example, non-ionic detergents such as Tween 80 and Triton X-100 have been reported to increase glucan synthesis by GTase(s) of $S$. sobrinus cultures, ${ }^{26-29}$ and similar findings have been obtained with other oral streptococci including $S$. salitarius and $S$. sanguis. ${ }^{30-32}$ The enhanced GTase production in these oral streptococci following addition of Tween 80 may be due either to changes in fatty acid composition of the cyloplasmic membranes, which in turn can lead to perturbations in proton motive force generation, ${ }^{31.32}$ or to simple resolution of GTase molecules from the enzyme aggregation, via lipophilic interaction in the presence of Tween $80 .{ }^{33}$ However, other investigators postulated strain or species variations in the effect of Tween 80 on GTase synthesis by several oral streptococcal species. ${ }^{34}$
In the present study non-ionic surfactants including Tween 80 did not affect the activities of GTases from $S$. sobrinus, whereas the activity of $S$. mutans CF-GTase, but not CA-GTase, was stimulated significantly. Thus it may be speculated that enhancement of GTase activities by non-ionic surfactants in mutans streptococci is due to activation of soluble glucan synthesis in S. mutans, whereas in S. sobrinus it is due to enhanced release of GTases during growth of the organisms.

Both cationic and anionic surfactants inhibit growth of many bacterial species, including oral streptococci, and also inhibit enzymic activities of GTases isolated from mutans streptococci. ${ }^{16,18.19,35-37}$ Generally it is agreed that cationic surfactants exert the most powerful bactericidal activity against mutans streptococci, followed by anionic surfactants $;^{16,19.37}$ non-ionic surfactants do not usually inhibit oral streptococci. ${ }^{37}$ However, Kabara ${ }^{16}$ claimed that the lauryl monoesters possess exceptionally powerful antimicrobial properties. Results obtained in this study (table 1) agree with the results reported by other investigators. ${ }^{16,18.19 .35 .37}$

Inhibition of glucan synthesis by various surfactants may be a factor in their ability to prevent dental plaque formation and induction of dental caries. ${ }^{18}$ It has been reported that anionic or cationic surfactants cause 
strong inhibition of GTases prepared from mutans streptococci, ${ }^{18,35}$ but the GTases used in these studies were not properly purified. In this study we used GTases from S. mutans and $S$. sobrinus that were highly purified by chromatography and we obtained new findings. In general it was shown that each GTase protein is affected by specific surfactants; e.g., nonionic detergents did not affect water-insoluble glucan synthesis by CA-GTase of $S$. mutans and GTase-I from $S$. sobrinus, but they profoundly enhanced watersoluble glucan synthesis of $S$. mutans CF-GTase and S. sobrinus GTase-Sa (figs. 1 and 2). Furthermore, $S$. sobrinus GTase-I was more sensitive to the inhibitory effect of ionic surfactants than the GTase-Sa or GTase-Sb of the organism.

Other features regarding the effects of surfactants on GTase, particularly in $S$. mutans, are that GTase activities are enhanced in the lower concentrations of cationic or ampholytic surfactants, but this is followed by a sharp decrease in GTases activities at higher concentrations of the same surfactants (fig. 1). A similar profile of GTase activities has been obtained ${ }^{38}$ lower concentrations of hydrogen peroxide stimulated

\section{References}

1. Hamada S, Slade HD. Biology, immunology, and cariogenicity of Streptococcus mutans. Microbiol Rev 1980; 44: 331-384.

2. Koga T, Asakawa H, Okahashi N, Hamada S. Sucrosedependent cell adherence and cariogenicity of serotype c Streptococcus mutans. $J$ Gen Microbiol 1986; 132: 2873-2883.

3. Tanzer JM, Freedman ML, Fitzgerald RJ, Larson $\mathrm{RH}$. Diminished virulence of glucan synthesis-defective mutants of Streptococcus mutans. Infect Immun 1974; 10: 197-203.

4. Hamada S, Koga T, Ooshima T. Virulence factors of Streptococcus mutans and dental caries prevention. $J$ Dent Res $1984 ; 63: 407-411$.

5. Paolino VJ, Kashket $\mathrm{S}$. Inhibition by cocoa extracts of biosynthesis of extracellular polysaccharide by human oral bacteria. Arch Oral Biol 1985; 30: 359-363.

6. Kashket S, Paolino VJ, Lewis DA, van Houte J. In-vitro inhibition of glucosyltransferase from the dental plaque bacterium Streptococcus mutans by common beverages and food extracts. Arch Oral Biol 1985; 30: 821-826.

7. Hattori M, Kusumoto IT, Namba T, Ishigami T, Hara $Y$. Effect of tea polyphenols on glucan synthesis by glucosyltransferase from Streptococcus mutans. Chem Pharm Bull 1990; 38: 717-720.

8. Newbrun E, Hoover CI, Walker GJ. Inhibition of acarbose, nojirimycin and 1-deoxynojirimycin of glucosyltransferase produced by oral streptococci. Arch Oral Biol 1983; 28 $531-536$.

9. Sela MN, Steinberg D, Segal R. Inhibition of the activity of glucosyl-transferase from Streptococcus mutans by glycyrrhizin. Oral Microbiol Immunol 1987; 2: 125-128.

10. Fukui K, Moriyama T. Effect of maltose on glucan synthesis by glucosyltransferases of Streptococcus mutans. Microbiol Immunol 1983; 27 : 917-927.

11. Koga T, Horikoshi T, Fujiwara T, Hamada S. Effects of panose on glucan synthesis and cellular adherence by Streptococcus mutans. Microbiol Immunol 1988; 32: 25-31.

12. Hamada $\mathrm{S}$, Torii $\mathbf{M}$. Interaction of glucosyltransferase from Streptococcus mutans with various glucans. J Gen Microbiol $1980 ; 116: 51-59$

13. Minami T, Fujiwara T, Ooshima T, Nakajima Y, Hamada S Interaction of structural isomers of sucrose in the reaction between sucrose and glucosyltransferases from mutans streptococci. Oral Microbiol Immunol 1990; 5: 189-194.

14. Ooshima T, Izumitani A, Minami T et al. Noncariogenicity of maltitol in specific pathogen-free rats infected with mutans streptococci. Caries Res 1992; 26: 33-37. insoluble glucan synthesis of $S$. sobrinus GTases, whereas higher concentrations of this agent caused complete inhibition of glucan production by GTase-S and GTase-I. This phenomenon may be due to crosslinking of the enzyme proteins through tyrosine residues or deamination of lysyl residues of GTase. ${ }^{38}$ Some surfactants, e.g., cationic or ampholytic, may induce hydrophobic or ionic interactions between GTases and a functional hydrophobic group within the surfactant molecule. It has been reported that some cationic surfactants inhibit experimental caries induction in hamsters, ${ }^{39}$ and that surfactants such as chlorhexidine digluconate and cetylpyridinium chloride prevented cellular co-aggregation between Prevotella spp. and Streptococcus spp. or Actinomyces spp. ${ }^{40}$

These findings indicate that topical application of aqueous solutions of these surfactants may result in reduced glucan synthesis and plaque accumulation due to inhibition of GTase activities and cell growth; this may eventually lead to a reduction in caries. Some of the surfactants used in this study have been used commercially in dentifrices and gargles.

15. Marsh PD. Dentifrices containing new agents for the control of plaque and gingivitis: microbiological aspects. $J$ Clin Periodontol 1991; 18: 462-467.

16. Kabara JJ. Structure-function rẻlationships of surfactants as antimicrobial agents. J Soc Cosmet Chem 1978; 29: 733-741.

17. Llenado RA, Jamieson RA. Surfactants. Anal Chem 1981; 53 : $174 \mathrm{R}-182 \mathrm{R}$.

18. Ciardi JE, Bowen WH, Rölla G. The effect of antibacterial compounds on glucosyltransferase activity from Streptococcus mutans. Arch Oral Biol 1978; 23: 301-305.

19. Tanzer JM, Slee AM, Kamay B, Scheer ER. In vitro evaluation of seven cationic detergents as antiplaque agents. Antimicrob Agents Chemother 1979; 15: 408-414.

20. Van der Ouderaa FJG. Anti-plaque agents. Rationale and prospects for prevention of gingivitis and periodontal disease. J Clin Periodontol 1991; 18: 447-454.

21. Hamada $\mathbf{S}$, Torii $\mathbf{M}$. Effect of sucrose in culture media on the location of glucosyltransferase of Streptococcus mutans and cell adherence to glass surfaces. Infect Immun 1978:20: 592-599.

22. Sato $S$, Koga $T$, Inoue $M$. Isolation and some properties of extracellular D-glucosyltransferases and Dfructosyltransferases from Streptococcus mulans serotypes $c, e$, and $f$. Carbohydr Res 1984; 134: 293-304.

23. Hamada S, Horikoshi T, Minami T, Okahashi N, Koga T. Purification and characterization of cell-associated glucosyltransferase synthesizing water-insoluble glucan from serotype c Streptococcus mutans. J Gen Microbiol $1989 ; 135$ : $335-344$.

24. Furuta $T$, Koga $T$, Nisizawa $T$, Okahashi $N$, Hamada $S$. Purification and characterization of glucosyltransferases from Streptococcus mutans 6715. J Gen Microbiol 1985; 131: 285-293.

25. Koga T, Okahashi N, Asakawa H, Hamada S. Adherence of Streptococcus mutans to tooth surfaces. In: Hamada S, Michalek SM, Kiyono H, Menaker HL, McGhee JR (eds) Molecular microbiology and immunobiology of Streptococcus mutans. Amsterdam, Elsevier Science Publishers. 1986: 111-120.

26. Umesaki Y, Kawai Y, Mutai M. Effect of Tween 80 on glucosyltransferase production in Streptococcus mutans. Appl Environ Microbiol 1977; 34: 115-119.

27. Sato $M$, Tsuchiya $\mathrm{H}$, Kato $\mathrm{M}$ et al. Effects of Tween 80 and sodium fluoride on extracellular glucosyltransferase production and membrane lipids of Streptococcus mutans. Int $J$ Biochem 1989; 21 : 751-754.

28. Wernette CM, San Clemente CL, Kabara JJ. The effect of 
surfactants upon the activity and distribution of glucosyltransferase in Streptococtus mutans 6715 Phamacol Therap Dent 1981: 6: 99-107.

29. Torii $\mathbf{M}$, Hamada $\mathrm{S}$. In titro inhibition of glucosyltransferase activity by surfactants. Abstracts of the 58th Meeting of the International Association for Dental Research 1980: 253.

30. Wittenberger CL, Beauman AJ. Lee LN. Tween 80 effect on glucosyl-transferase synthesis by Streptococcus salitarius. $J$ Bacteriol 1978: 133: 231-239.

31. West AA, Whiley RA, Marsh PD. Keevil CW. The relationship between glycosyltransferase production and membrane fatty acid composition of Streptococtus samyuis NCTC 7865 grown in the presence of protonmotive force inhibitors. $J$ Gen Microhiol 1987: 133: 2601-2606.

32. Markevics LJ. Jacques NA. Enhanced secretion of glucosyltransferase by changes in potassium ion concentration is accompanied by an altered pattern of membrane fatty acids in Stroptococtus salitarias. J Bacteriol 1985: 161: 989.994.

33 Figures WR. Edwards JR. Resolution of the glycosyltransferase activities from two strains of Streptococcus mutams by polyacrylamide gel electrophoresis in the presence of Tween 80. Biachim Biophls .4cta 1979; 577: 142-146.
34. Buchan RJ, Jenkinson HF, Glucosyltransferase production by Streptococcus sanguis Challis and comparison with other oral streptococci. Oral Microbiol Immunol 1990; 5: 63-71.

35. Jablonski WM, Hayashi JA. Inhibition of extracellular streptococcal enzymes. $J$ Dent Res $1970 ; 49: 178$.

36. Christensen F, Kilian M. The effect of chlorhexidine and some other detergents on the activity of dextransucrase from Streptococcus mutans. Acta Odont Scand 1975; 35: 119-123.

37. Lim JK, Smith S. McGlothlin J, Gerencser VF. Minimum inhibitory concentration of surfactants for plaque antiadherents. Caries Res 1982: 16: 440-442.

38. McAlister D, Nambiar S, Taylor KG, Doyle RJ. Glucosyltransferases of Streptococcus sobrinus C211 are both stimulated and inhibited by hydrogen peroxide. Oral Microbiol Immunol 1989; 4: 146-152.

39. Tamura T. Gron P. Caslavska V, Kent R. Effect of fluoride and selected cationic surfactants on caries in rodents. Caries Res 1987; $21: 526-529$.

40. Smith RN. Andersen RN, Kolenbrander PE. Inhibition of intergeneric coaggregation among oral bacteria by cetylpyridinium chloride, chlorhexidine digluconate and octenidine dihydrochloride. J Periodont Res 1991; 26: 422-428. 